\title{
Analysis of the Influence of Opinion Leaders on Public Emergencies through Microblogging
}

\author{
Wei Fang1, Binli Gao ${ }^{2 *}$, Nan $\mathrm{Li}^{1}$ \\ ${ }^{1}$ Chengdu Sports University, Chengdu, China \\ ${ }^{2}$ Department of Hyperbaric Oxygen Treatment Center, Sichuan Academy of Medical Sciences and Sichuan Provincial People's \\ Hospital, University of Electronic Science and Technology of China, Chengdu, China \\ Email: ^582621550@qq.com
}

How to cite this paper: Fang, W., Gao, B. L., \& Li, N. (2020). Analysis of the Influence of Opinion Leaders on Public Emergencies through Microblogging. Open Journal of Social Sciences, 8, 154-158. https://doi.org/10.4236/jss.2020.85010

Received: April 22, 2020

Accepted: May 15, 2020

Published: May 18, 2020

Copyright (c) 2020 by author(s) and Scientific Research Publishing Inc. This work is licensed under the Creative Commons Attribution International License (CC BY 4.0).

http://creativecommons.org/licenses/by/4.0/

\begin{abstract}
This article aims to analyze the characteristics of microblogging opinion leaders in the event as well as their influence on public emergencies. It finds microblog celebrities (often VIP users) have become the leaders of public opinions, and microblogs on government affairs help all levels of departments combat the outbreak. Conclusively when China was fighting against COVID-19, opinion leaders in the Weibo field applied their influence to the reconstruction of related topics, released as much positive information as possible, hence conducing to positive anti-epidemic sentiment as well as a successful battle against COVID-19.
\end{abstract}

\section{Keywords}

Influence of Opinion Leaders, Public Emergencies, Microblogging

\section{Introduction}

According to the 44th Statistical Report on Internet Development in China, recently released by the China Internet Network Information Center (CNNCI), as of June 2019, the number of netizens in China amounted to 854 million, of which $99.1 \%$ (847 million) were mobile users. And mobile net-news users also reached 660 million (CNNIC, 2019). As for the use of social media applications, the average daily active users of Weibo were 220 million, who spent 34 minutes on average each day in December 2019. Characterized by time-varying and "explosive" communication mechanisms, Microblogging has gradually become an independent field for public opinions. With traditional media stepping in, it has also helped traditional media to achieve mass communication through social networks, thus becoming another choice of pseudo-environment. As the center 
and important nodes of microblogging, opinion leaders are playing a guiding role in the generation and evolution of public opinions (Wang \& Xie, 2012). On December 31, 2019, the Wuhan Municipal Health Commission issued a notice saying that 27 COVID-19 pneumonia cases were recently found in some medical institutions in Wuhan, Hubei. Then on January 31, 2020, the World Health Organization stated that the COVID-19 outbreak in China has evolved into a public health emergency of international concern (PHEIC). Both incidents have engaged microblogging as an important voice channel. Taking China's fight against the corona-virus epidemic as the case of study, this article aims to analyze the characteristics of microblogging opinion leaders in the event as well as their influence on public emergencies.

\section{Opinion Leaders Try to Crack Down on COVID-19 through Microblogging}

The definition of opinion leader is derived from the two-step flow communication theory proposed by communication scholars Paul Lazarsfeld and Elihu Katz in the 1940s. Lazarsfeld defined the person in interpersonal network who has an active influence on the transmission of information to others as "opinion leader", and he also defined the process where information is filtered by the mass media through opinion leaders and then flows to individuals as the "two-step flow of communication" theory (Liu, 2008).

\subsection{Microblog Celebrities (Often VIP Users) Have Become the Leaders of Public Opinions}

Those "VIP celebrities" usually refers to active "public figures" who boast a large group of fans on microblog. Microblog users' emotions vary from person to person, so they tend to believe those "VIP celebrities" they're following when judging the events that has happened. With a wide range of identities, "VIP celebrities" may be entertainment stars, tourism or education micro-bloggers, and the like. During the epidemic, most entertainment celebrities tried to express positive opinions. For instance, the topic of "Han Hong Offering Assistance to Wuhan" has been read 1.3 billion times, triggering 1.044 million discussions. Good news including "Tribute to the Most Beautiful Women", "Xiangyang, Hubei Has Lifted the Ban", "Zero Infection Growth in Wuhan, Hubei" released by celebrities in other fields, such as the top ten celebrities Ms. British News, A Special Account for Memories, and Guda Baihua, and so on, have attained countless reposts as well as comments.

As James T. Yong mentioned in his book Government by the People in 1923, public opinion means the social judgement made by a self-aware group after public discussions on issues of common concern (Liu, 2015). Although microblog celebrities cannot directly control what netizens say, they can strengthen the positive agenda setting and guide public opinion through their influence, thus to a certain extent reducing public fears and even curbing the spread of negative information. 


\subsection{Microblogs on Government Affairs Help All Levels of Departments Combat the Outbreak}

Microblogs on government affairs are those set for public affairs on behalf of government agencies and officials. They are official online interaction platforms for collecting opinions, releasing information, as well as serving the public. The reason why they are different from other microblog communication subjects is because of the nature of specificity and communication (for microblogging and government management). Until June 2019, there have been 138,253 certified governmental microblog accounts in China. During the anti-epidemic period, the government-affair microblogs have been an important channel for the official disclosure of epidemic information, the release of prevention and control policies, and the avoidance of rumors. From January 22 to February 15, more than 30,000 government-affair microblogs posted information about the outbreak, with over 14.3 million posts read 43.2 billion times and reposted 14.79 million times. Hubei Provincial Government's microblogging data was quite impressive. Especially on March 19 when the microblog of "0 New Infection" was published, it generated effective views of 13.55 million times and discussions of 16,697 times respectively.

In the face of major events, the more the government obscures the truth, the harder the public get answers, hence bringing about confusions and conjectures. And another problem at present is that the information quality of user interaction remains difficult to control. On top of that, government agencies managed to set up a self-media matrix on Weibo so as to issue first-hand epidemic information. Based on netizens' frequent use of Weibo, government-affair microblogs have reduced the retelling to a certain extent, thus ensuring the information to be true and accurate without misinterpretation.

Through the habit analysis of Weibo users, we find that netizens do not focus on only a single "VIP celebrity" or a single government-affair microblog. So in the public opinion field of microblog, there will not be only one opinion leader within the user group, which also confirms what Everett M. Rogers has proposed-"N-step" (multi-step) influence communication will go through intermediary hypothesis of multiple opinion leaders. As a result, the unpredictability of changes in public opinions will largely grow.

The influence of opinion leaders on public emergencies on Weibo can be tested through popular topics and users' emotion changes.

By collating COVID-19 microblogs from January 1st to March 19th (the zero infection growth day in Hubei Province), netizens' emotions were going through following changes: In the panic and anxiety period, topics such as "One Patient in Wuhan Thought He Was Having a Cold after the Onset of COVID-19 for More than 10 Days" and "China Has 217 Confirmed Cases of COVID-19" were among the most searched hashtags for quite a while. Then topics such as "Cheer up, Wuhan", "China Will Win", and "The Most Beautiful and Brave People" and the like, initiated by some government media and Weibo celebrities, caused 
heated discussions, which reflected the positive transformation of people's mood from being panic to being confident. As the epidemic went under control, patients gradually got recovered and confirmed diagnoses continued to decrease, the hottest Weibo topics were awarded to "Your Most Wanted Food When the Epidemic Is Gone", "What Your Mothers Says the Most during the Epidemic", "The Most Touching Thing Recently", under which the comment "All the people across the country are battling against COVID-19 with jointed efforts" got the maximum likes. It is through microblogging that netizens managed to express their positive spirits and share touching moments.

\section{The Influence Test of Microblog Opinion Leaders during the Epidemic}

Through the habit analysis of Weibo users, we find that netizens do not focus on only a single "VIP celebrity" or a single government-affair microblog. So in the public opinion field of microblog, there will not be only one opinion leader within the user group, which also confirms what Everett M. Rogers has proposed-"N-step" (multi-step) influence communication will go through intermediary hypothesis of multiple opinion leaders. As a result, the unpredictability of changes in public opinions will largely grow.

The influence of opinion leaders on public emergencies on Weibo can be tested through popular topics and users' emotion changes.

By collating COVID-19 microblogs from January 1st to March 19th (the zero infection growth day in Hubei Province), netizens' emotions were going through following changes: In the panic and anxiety period, topics such as "One Patient in Wuhan Thought He Was Having a Cold after the Onset of COVID-19 for More than 10 Days" and "China Has 217 Confirmed Cases of COVID-19" were among the most searched hashtags for quite a while. Then topics such as "Cheer up, Wuhan", "China Will Win", and "The Most Beautiful and Brave People" and the like, initiated by some government media and Weibo celebrities, caused heated discussions, which reflected the positive transformation of people's mood from being panic to being confident. As the epidemic went under control, patients gradually got recovered and confirmed diagnoses continued to decrease, the hottest Weibo topics were awarded to "Your Most Wanted Food When the Epidemic Is Gone", "What Your Mothers Says the Most during the Epidemic", "The Most Touching Thing Recently", under which the comment "All the people across the country are battling against COVID-19 with jointed efforts" got the maximum likes. It is through microblogging that netizens managed to express their positive spirits and share touching moments.

\section{Conclusion}

When China was fighting against COVID-19, opinion leaders in the Weibo field applied their influence to the reconstruction of related topics, released as much positive information as possible, and guided netizens, with the focus on positive 
emotions, to continuously strengthen existing opinions under the influence of social groups with relative consensus, hence conducing to positive anti-epidemic sentiment as well as a successful battle against COVID-19.

\section{Conflicts of Interest}

The authors declare no conflicts of interest regarding the publication of this paper.

\section{References}

CNNIC (2019). The 44th Statistical Report on the Development of China's Internet. http://www.cac.gov.cn/2019-08/30/c_1124939590.htm

Liu, H. (2008). Theory of Mass Communication: Paradigms and Schools (p. 171). Beijing: China Renmin University Press.

Liu, J. (2015). Ten Theorems of Western Public Opinion. News Lovers, No. 4, 39-44.

Wang, P., \& Xie, Y. (2012). An Empirical Study on Opinion Leaders of Microblog in Public Emergencies-Taking "Wenzhou Motor Train Accident" as an Example. Journal of China Media University, 34, 82-88. 